\title{
Therapeutic effects of the dipeptidyl peptidase-IV inhibitor, sitagliptin, on non-alcoholic steatohepatitis in FLS-ob/ob male mice
}

\author{
TAKUMI ONOYAMA, MASAHIKO KODA, TOSHIAKI OKAMOTO, MANABU KISHINA, \\ TOMOMITSU MATONO, TAKAAKI SUGIHARA and YOSHIKAZU MURAWAKI \\ Division of Medicine and Clinical Science, Department of Multidisciplinary Internal Medicine, \\ Faculty of Medicine, Tottori University, Yonago 683-8504, Japan
}

Received November 23, 2014; Accepted August 17, 2015

DOI: $10.3892 / \mathrm{mmr} .2015 .4329$

\begin{abstract}
Non-alcoholic steatohepatitis is characterized by hepatic fat accumulation, inflammation and varying degrees of fibrosis. The dipeptidyl peptidase-IV enzyme is important in glucose metabolism, as well as lipid accumulation, extracellular matrix metabolism and immune stimulation. Furthermore, the enzyme activity of dipeptidyl peptidase-IV is known to be increased in non-alcoholic steatohepatitis. Therefore, dipeptidyl peptidase-IV inhibitors are potential therapeutic agents for non-alcoholic steatohepatitis. The present study assessed the therapeutic effects of sitagliptin, a dipeptidyl peptidase-IV inhibitor, on non-alcoholic steatohepatitis using fatty liver Shionogi- $o b / o b$ male mice. Sitagliptin $(2 \mathrm{mg} / \mathrm{kg} / \mathrm{day} ; \mathrm{n}=10)$ or placebo (control; $\mathrm{n}=10$ ) was orally administered to fatty liver Shionogi-ob/ob mice for 12 weeks, and hepatic steatosis,
\end{abstract}

Correspondence to: Professor Masahiko Koda, Division of Medicine and Clinical Science, Department of Multidisciplinary Internal Medicine, Faculty of Medicine, Tottori University, Nishi-Machi 36-1, Yonago 683-8504, Japan

E-mail: masakoda@grape.med.tottori-u.ac.jp

Abbreviations: NASH, non-alcoholic steatohepatitis; DPP, dipeptidyl peptidase; NAFLD, on-alcoholic fatty liver disease; FLS, fatty liver shionogi; MCD, methionine/choline-deficient; AST, aminotransferase; ALT, alanine aminotransferase; HSC, hepatic stellate cell, SMA, $\alpha$-smooth muscle actin; 8-OHdG, 8-hydroxy-2-deoxyguanosine; 4-HNE, 4-hydroxynonenal; TUNEL, terminal deoxynucleotidyl transferase dUTP nick end labeling; PCR, polymerase chain reaction; TGF- $\beta 1$, transforming growth factor- $\beta 1$; CTGF, connective tissue growth factor; TNF- $\alpha$, tumor necrosis factor- $\alpha$; MCP-1, monocyte chemoattractant protein-1; TIMP-1, tissue inhibitor of metalloproteinases-1; PPAR- $\alpha$, peroxisome proliferator activated receptor; SREBP1c, sterol regulatory element-binding protein 1c; FAS, fatty acid synthase; MTP, microsomal triglyceride transfer protein

Key words: non-alcoholic steatohepatitis, sitagliptin, fatty liver Shionogi-ob/ob mice, dipeptidyl peptidase-IV inhibitor, hepatic fibrosis, oxidative stress, hepatic stellate cell, apoptosis fibrosis, inflammation and oxidative stress were assessed in comparison with the controls. Sitagliptin administration reduced body weight and blood glucose levels, and improved hepatic fibrosis. It also inhibited the gene expression levels of fatty acid synthase, transforming growth factor- $\beta 1$, tissue inhibitor of metalloproteinases-1, procollagen-type 1 , tumor necrosis factor- $\alpha$, monocyte chemoattractant protein- 1 and enhanced peroxisome proliferator activated receptor- $\alpha$. Furthermore, a marked attenuation of hepatic stellate cell activation and Kupffer cells was observed in the sitagliptin group. A decrease in oxidative stress and apoptosis was also observed. Sitagliptin attenuated the progression of hepatic fibrosis by improving lipid metabolism, inflammation and oxidative stress in non-alcoholic steatohepatitis.

\section{Introduction}

Non-alcoholic steatohepatitis (NASH) is characterized by hepatic fat accumulation, inflammation and varying degrees of fibrosis. The central pathophysiological issue in patients afflicted with NASH is insulin resistance. Improvement of insulin resistance has therapeutic potential in preventing the progression of NASH (1). Previously, dipeptidyl peptidase (DPP)-IV inhibitors have been used as novel oral drugs for the treatment of type 2 diabetes. DPP-IV is an enzyme, which inactivates incretins, including glucagon-like peptide-1 and gastric inhibitory polypeptide, which regulates blood glucose primarily via stimulation of glucose-dependent insulin release. As a result, the activation of DPP-IV leads to the development of glucose intolerance and hepatic steatosis (2). DPP-IV enzyme has widespread organ distribution throughout the body and has pleiotropic biological functions (3-5). DPP-IV is involved in glucose metabolism and lipid accumulation, degradation of the extracellular matrix, appetite regulation and immune stimulation via its peptidase activities (6-10). The liver is one of the organs expressing DPP-IV to a high degree (11). The mRNA expression of DPP-IV is also increased in the liver of non-alcoholic fatty liver disease (NAFLD) (12). Serum DPP-IV activity and the expression of hepatic DPP-IV are correlated with hepatic steatosis and NAFLD severity (13). DPP-IV deficient rats exhibit a reduction of hepatic steatosis, hepatic 
inflammatory and pro-fibrogenic cytokines compared with the wild-type rats (14). Therefore, DPP-IV may be involved in not only insulin resistance, but also hepatic lipogenesis, inflammation and fibrosis during the progression of NASH. Therefore, DPP-IV inhibitors may have favorable effects for four pathways in the treatment of NASH, including insulin resistance, hepatic lipogenesis, inflammation and fibrogenesis.

Fatty liver Shionogi (FLS)-ob/ob mice are generated by transferring the $L e p^{o b}$ gene into the genome of FLS mice without obesity, which then spontaneously develop chronic hepatic steatosis. The features of FLS-ob/ob mice are hyperphagia, obesity, hyperlipidemia and diabetes mellitus (15). They exhibit histologically severe steatosis, hepatocellular ballooning and advanced hepatic fibrosis, increased oxidative stress, elevated inflammatory, as well as pro-fibrotic cytokine production, increased apoptosis of hepatocytes and the mice also develop cirrhosis and liver tumors $(16,17)$. FLS-ob/ob mice are the closest animal model to metabolic syndrome-associated NASH in humans and possess targets of DPP-IV inhibitors. Previously, sitagliptin, a DPP-IV inhibitor, was reported to attenuate methionine/choline-deficient (MCD) diet-induced steatohepatitis (18). However, this model is markedly different compared with the features of human NASH. The present study aimed to confirm whether sitagliptin improved steatohepatitis in the FLS-ob/ob mice by modifying insulin resistance, hepatic lipogenesis, inflammation, fibrosis and oxidative stress.

\section{Materials and methods}

Animals. Twenty male FLS-ob/ob mice (age, 8 weeks; body weight, 40.14 $\pm 3.39 \mathrm{~g}$ ) were obtained from Shionogi Research Laboratories (Shiga, Japan) and housed under a controlled temperature of $24 \pm 2^{\circ} \mathrm{C}$ and a 12 -h light/dark cycle. The mice were provided with water and standard powder chow (CE-2, 4.6\% fat; CLEA Japan, Inc., Tokyo, Japan) ad libitum. Food consumption and body weight were monitored throughout the observation period to equalize the dietary intake between the two groups. All experiments were performed in accordance with the Animal Experimentation Guidelines of Tottori University (Yonago, Japan). The study was approved by the ethics committee of Tottori University, Yonago, Japan (approval no. 11-Y-54).

Administration of sitagliptin. Male FLS-ob/ob 12-week-old mice were randomly assigned to the control or sitagliptin group ( $\mathrm{n}=10 /$ group). Sitagliptin (2 mg/kg/day; Merck \& Co., Inc, Kenilworth, NJ, USA) was administered as a bolus every afternoon per os. for 12 weeks through a gastric tube. The control group was administered water. Blood was drawn from the tail vein after $4 \mathrm{~h}$ fasting and the blood glucose level was measured every 4 weeks. After 12 weeks, the animals were sacrificed under pentobarbital anesthesia (Dainippon Sumitomo Pharma, Osaka, Japan) and blood was collected from the right ventricle. The plasma samples were frozen and stored at $-80^{\circ} \mathrm{C}$. The liver and visceral fat were weighed, snap frozen in liquid nitrogen and stored at $-80^{\circ} \mathrm{C}$. Liver specimens were also fixed in $10 \%$ buffered formalin (Wako Pure Chemical Industries, Ltd., Osaka, Japan) and embedded in paraffin (Wako Pure Chemical Industries, Ltd.) for histological analysis.
Analysis of hepatic cholesterol and triglyceride contents. Snap frozen liver samples (50 $\mathrm{mg}$ ) were homogenized and extracted with chloroform-methanol (2:1, v/v; Wako Pure Chemical Industries, Ltd.), and subsequently the organic phase was dried and resuspended in 2-propanol, containing $10 \%$ Triton X-100. The total cholesterol and triglyceride levels were measured using a Cholesterol E-test (Wako Pure Chemical Industries, Ltd.) and a Triglyceride E-test (Wako Pure Chemical Industries, Ltd.), respectively.

Biochemical analyses. The blood samples were immediately separated via centrifugation at 2,000 $\mathrm{x}$ for $15 \mathrm{~min}$ at $4^{\circ} \mathrm{C}$, and were stored at $-80^{\circ} \mathrm{C}$ until further use. The serum samples were analyzed to determine the levels of aspartate aminotransferase (AST) and alanine aminotransferase (ALT).

Measurement of areas of hepatic steatosis. Neutral lipids in frozen-fixed, cryostat-embedded liver sections (4- $\mu \mathrm{m}$ thick) were stained with Oil Red O (Sigma-Aldrich, St. Louis, MO, USA). The areas of hepatic steatosis were subsequently measured in 10 randomly selected fields (magnification, $\mathrm{x} 400$; Olympus BX51N-34; Olympus Corporation, Tokyo, Japan) in each specimen using Win ROOF version 5.71 software (Mitani Corporation, Tokyo, Japan).

Measurement of hepatic fibrosis area with sirius red staining. Formalin-fixed, paraffin-embedded liver sections ( $4 \mu \mathrm{m}$ thick) were stained with Picrosirius red (Chroma-Gesellschaft Schmid GmbH \& Co., Münster, Germany) and counterstained with fast green (Chroma-Gesellschaft Schmid GmbH \& Co.). The areas of hepatic fibrosis were subsequently measured in 10 randomly selected fields in each specimen (magnification, $\mathrm{x} 400$ ) using Win ROOF version 5.71 software and the Olympus BX51N-34 microscope.

Immunostaining for $\alpha$-smooth muscle actin (SMA). The present study immunohistochemically detected $\alpha$-SMA by staining with mouse monoclonal anti- $\alpha$-SMA antibody (cat. no. MS-113-R7; Thermo Fisher Scientific, Fremont, CA, USA) without dilution. Goat anti-mouse Ig, from the Histofine ${ }^{\circledR}$ Mouse Stain kit (cat. no. 414322; Nichirei Biosciences, Inc., Tokyo, Japan), was used as the secondary antibody without dilution. The activation of hepatic stellate cells (HSC) was assessed by measuring the areas of $\alpha$-SMA staining using Win ROOF version 5.71 software in 10 randomly selected fields (magnification, x400; Olympus BX51N-34 microscope) in each specimen.

Analysis of inflammatory cell infiltration of liver tissue. F4/80, which is a mature mouse cell surface glycoprotein expressed at high levels on Kupffer cells (19), was immunohistochemically stained using a rat monoclonal anti-F4/80 mouse antibody (cat. no. ab6640; Abcam, Tokyo, Japan) diluted at 1:100 with $0.01 \mathrm{M} / 1$ phosphate-buffered saline (PBS), according to the manufacturer's instructions. Goat anti-rat secondary antibody, from the Histofine ${ }^{\circledR}$ Simple Stain ${ }^{\text {TM }}$ Mouse MAX-PO (Rat) kit (cat. no. 414311; Nichirei Biosciences, Inc.) was used without dilution. The immunopositive cells were analyzed in 10 intralobular ocular fields (magnification, x400; Olympus BX51N-34 microscope) in each specimen. 


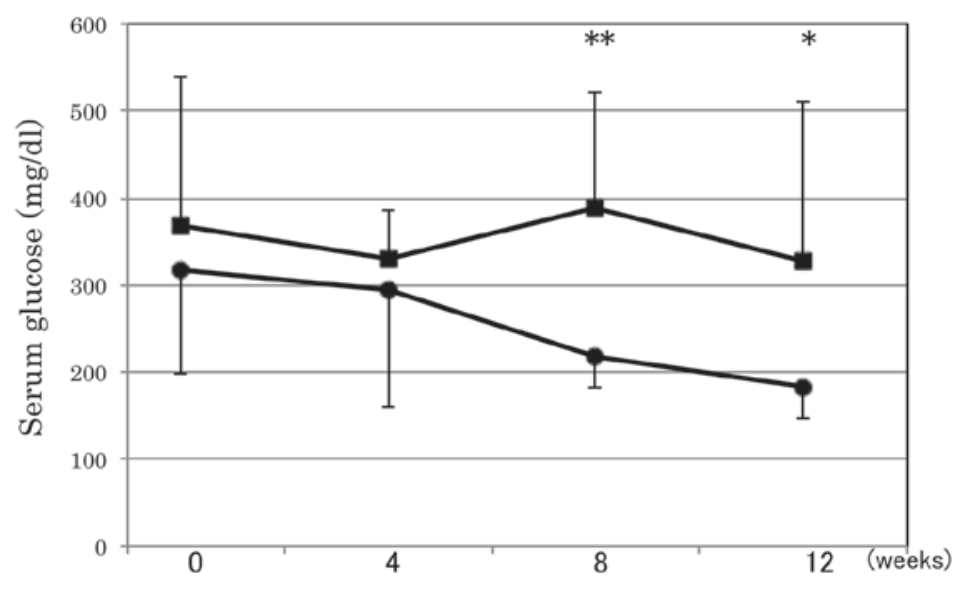

After DPP-IV inhibitor administration

Figure 1. Effect of sitagliptin administration on serum glucose levels in mice. The levels of serum glucose were significantly lower in the sitagliptin group (•) compared with the control group ( $\square$ ) at 8 and 12 weeks. ${ }^{*} \mathrm{P}<0.05$ and ${ }^{* *} \mathrm{P}<0.01$, compared with the control group.

Table I. Effects of sitagliptin administration on various characteristics of the mice.

\begin{tabular}{lcc}
\hline Characteristic & $\begin{array}{c}\text { Control } \\
\text { group }(\mathrm{n}=10)\end{array}$ & $\begin{array}{c}\text { Sitagliptin } \\
\text { group }(\mathrm{n}=10)\end{array}$ \\
\hline Body weight $(\mathrm{g})$ & $56 \pm 8$ & $48 \pm 9^{\mathrm{a}}$ \\
Liver weight $(\mathrm{g})$ & $7.8 \pm 2.5$ & $6.0 \pm 2.7$ \\
Liver/body weight ratio & $0.14 \pm 0.03$ & $0.12 \pm 0.04$ \\
Visceral fat weight (g) & $2.3 \pm 0.4$ & $2.2 \pm 0.6$ \\
Weekly dietary intake (g) & $37 \pm 12$ & $36 \pm 10$ \\
Serum AST (U/l) & $183 \pm 73$ & $158 \pm 61$ \\
Serum ALT (U/l) & $226 \pm 107$ & $232 \pm 195$ \\
\hline
\end{tabular}

${ }^{a} \mathrm{P}<0.05$ and ${ }^{\mathrm{b}} \mathrm{P}<0.01$, compared with the control group. AST, aspartate aminotransferase; ALT, alanine aminotransferase.

Analysis of oxidative stress. Oxidative stress was assessed by immunohistochemical staining to detect 8-hydroxy-2-deoxyguanosine (8-OHdG), a marker of oxidative DNA damage (16), using a monoclonal mouse anti-8-OHdG antibody (cat. no. MOG-020P; Nikken SEIL, Shizuoka, Japan), diluted with $200 \mu \mathrm{l}$ distilled water, according to the manufacturer's instructions. Goat anti-mouse Ig, from the Histofine ${ }^{\circledR}$ Mouse Stain kit, served as the secondary antibody without dilution. The immunopositive cells were analyzed using Win ROOF version 5.71 software in 10 intralobular ocular fields (magnification, x400; Olympus BX51N-34 microscope) in each specimen, and the values were expressed as the ratios (\%) of fields. Furthermore, the present study semi-quantified 4-hydroxynonenal (4-HNE), which was immunohistochemically stained using a monoclonal mouse anti-4-HNE antibody (cat. no. MHN-020P; Nikken SEIL), diluted with $200 \mu 1$ distilled water, according to the manufacturer's instructions. Goat anti-mouse Ig, from the Histofine ${ }^{\circledR}$ Mouse Stain kit, was used as the secondary antibody without dilution. A total of 10 randomly selected fields in each specimen, which were stained with 4-HNE (magnification, $x 400$ ) were classified into immunopositive grades $1,2,3$ or $4(0-10 \%, 11-20 \%, 21-30 \%$ and $>30 \%$, respectively) and the mean values of the 10 fields were calculated.

Analysis of apoptotic cells in liver tissue. The apoptotic cells in liver tissue were detected in situ by specific labeling of nuclear DNA fragmentation using terminal deoxynucleotidyl transferase dUTP nick end labeling (TUNEL). The sections were deparaffinized in xylene, rehydrated, washed with PBS and digested with $20 \mu \mathrm{g} / \mathrm{ml}$ proteinase $\mathrm{K}$ (Wako Pure Chemical Industries, Ltd.) for $10 \mathrm{~min}$ at room temperature. The fragmented DNA was detected via the TUNEL method using the Apop Tag Plus Peroxidase In Situ Apoptosis Detection kit (EMD Millipore, Billerica, MA, USA), according to the manufacturer's instructions. The numbers of stained and unstained cells were counted using Win ROOF version 5.71 software in 10 intralobular ocular fields (magnification, $\mathrm{x} 400$ ) in each specimen.

$R N A$ extraction and reverse transcription-quantitative polymerase chain reaction $(R T-q P C R)$ analysis. Hepatic tissue samples were homogenized and the total RNA was extracted using the RNeasy Lipid Tissue Mini kit (Qiagen, Hilden, Germany). The RNA concentrations were determined by measuring the absorbance at $260 \mathrm{~nm}$ using a NanoDrop 1000 spectrophotometer (Thermo Fisher Scientific), and the RNA quality was confirmed by electrophoresis on ethidium bromide stained $1 \%$ agarose gels. The total RNA $(2 \mu \mathrm{g})$ was reverse transcribed in a final volume of $11.5 \mu 1$, containing $4 \mu \mathrm{l} 5 \mathrm{X}$ standard buffer, $2 \mu \mathrm{l} 0.1 \mathrm{M}$ dithiothreitol, $1 \mu \mathrm{l}$ SuperScript II RNase H reverse transcriptase (Invitrogen Life Technologies, Carlsbad, CA, USA), $2 \mu 110$ mM dNTP (Promega, Madison, WI, USA), $1 \mu 150 \mathrm{pmol} / \mu 1$ random primer (Promega), $0.5 \mu \mathrm{l} 100 \mathrm{pmol} / \mu \mathrm{l}$ oligo (dt) 15 Primer (Promega) and $1 \mu 140 \mathrm{U} / \mu 1$ ribonuclease inhibitor (Wako Pure Chemical Industries, Ltd.). The mixtures were incubated at $37^{\circ} \mathrm{C}$ for $60 \mathrm{~min}, 95^{\circ} \mathrm{C}$ for $5 \mathrm{~min}$ and subsequently cooled to $4^{\circ} \mathrm{C}$ for 5 min using a MyCycler ${ }^{\mathrm{TM}}$ Thermal Cycler (Bio-Rad Laboratories, Inc., Hercules, CA, USA).

Real-time PCR. Quantitative real-time PCR assays (7900HT Fast Realtime PCR system; Applied Biosystems 
H.E.

Oil red

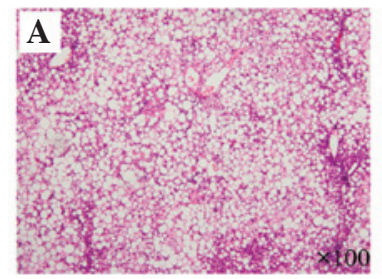

Control

$\mathbf{E}$

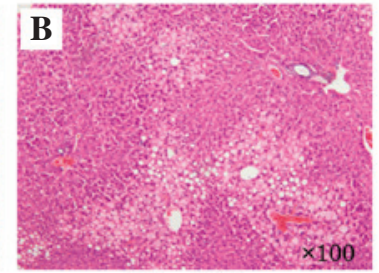

Sitagliptin

F

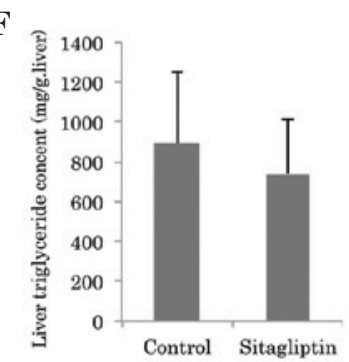

Sirius red

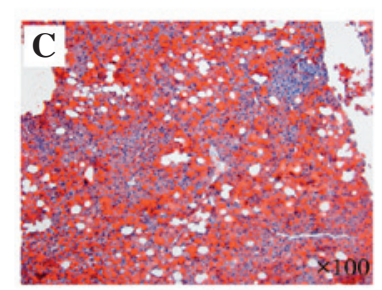

Control

G

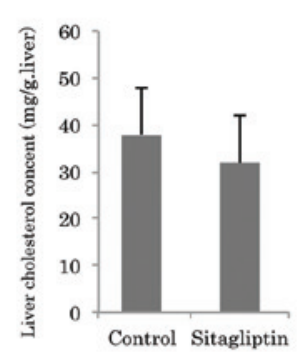

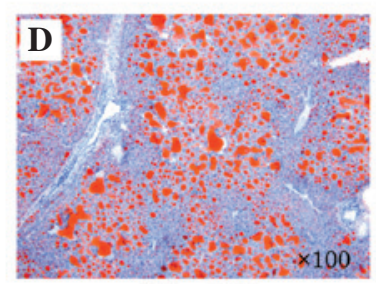

Sitagliptin

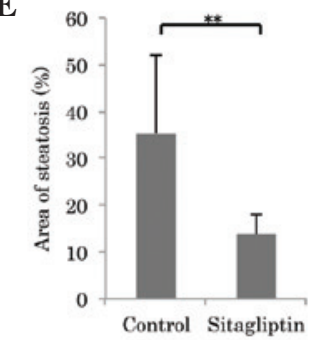

a-SMA

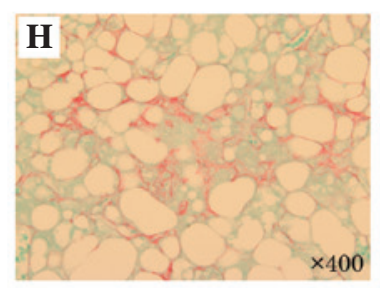

Control

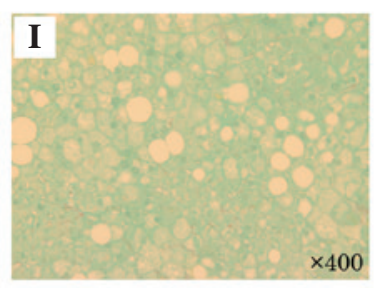

Sitagliptin

M

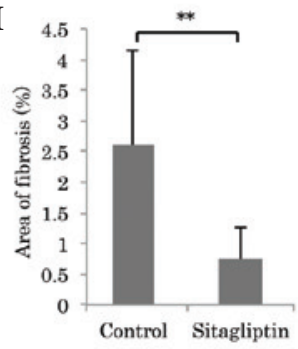

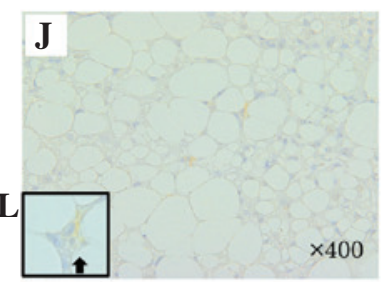

Control

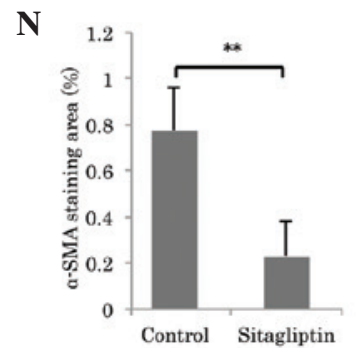

Figure 2. Histological analyses of liver tissues. Representative images of the H.E. staining (magnification, $\mathrm{x} 100$ ) of the (A) control group and (B) sitagliptin groups . Representative images of Oil Red O staining (magnification, $x 100$ ) in the (C) control and (D) sitagliptin groups. (E) The proportion (\%) of hepatic steatosis area stained with Oil Red $\mathrm{O}$ was measured using image analysis ( $\left.{ }^{* *} \mathrm{P}<0.01\right)$. A comparison of $(\mathrm{F})$ hepatic triglyceride content and $(\mathrm{G})$ hepatic cholesterol content between the groups. Hepatic fibrosis was determined by Sirius red staining. Representative images of sirius red staining of the (H) control and (I) sitagliptin groups. Representative images of $\alpha$-SMA immunostaining in the (J) control and $(\mathrm{K})$ sitagliptin groups (magnification, $\mathrm{x} 400)$. (L) demonstrates a higher magnification $(\mathrm{x} 1,000)$ of an $\alpha$-SMA positive cell. (M) The proportion (\%) of hepatic fibrosis area stained with Sirius red (magnification, $\mathrm{x} 400)$ was measured using image analysis $\left({ }^{* *} \mathrm{P}<0.01\right)$. The area of fibrosis was significantly decreased in the sitagliptin group compared with the control group. (N) Quantitation of an area of $\alpha$-SMA immunostaining measured by image analysis $\left({ }^{* *} \mathrm{P}<0.01\right)$. The areas of $\alpha$-SMA immunostaining were significantly reduced in the sitagliptin group compared with the control. H.E., hematoxylin and eosin; $\alpha$-SMA, $\alpha$-smooth muscle actin.

Life Technologies, Foster City, CA, USA) were performed in a final volume of $10 \mathrm{ml}$, containing $250 \mathrm{nM}$ Universal ProbeLibrary probe (Roche, Basel, Switzerland), $900 \mathrm{nM}$ forward primer, $900 \mathrm{nM}$ reverse primer, $5 \mathrm{ml}$ EXPRESS qPCR Supermix with Premixed Rox (Invitrogen Life Technologies) and $2 \mathrm{ml}$ cDNA. The mRNA expression levels of transforming growth factor- $\beta 1$ (TGF- $\beta 1$; GenBank, NM_011577), procollagen-type I (GenBank, U08020), connective tissue growth factor (CTGF; GenBank, NM_010217), tumor necrosis factor- $\alpha$ (TNF- $\alpha$; GenBank, NM_013693), monocyte chemoattractant protein-1
(MCP-1; GenBank, NM_100127112), tissue inhibitor of metalloproteinases-1 (TIMP-1; GenBank, NM_011593), peroxisome proliferator activated receptor (PPAR- $\alpha$; GenBank, NM_007988.3), sterol regulatory element-binding protein 1c (SREBP1c; GenBank, NM_011480), fatty acid synthase (FAS; GenBank, AF127033) and microsomal triglyceride transfer protein (MTP; GenBank, NM_008642) were assessed using the 7900HT Fast Real-Time PCR system with SDS2.3 software (Applied Biosystems Life Technologies) and $\beta$-actin (GenBank, NM_007393) was used as an internal standard. The thermal cycle conditions were 
F 4/80

8-OHdG

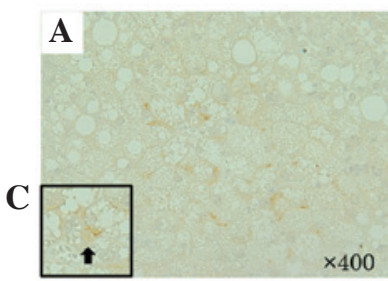

Control

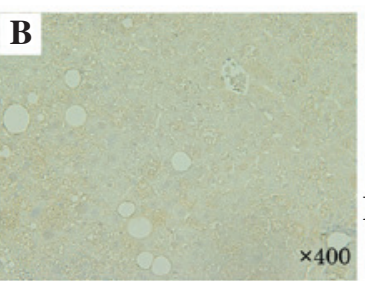

Sitagliptin

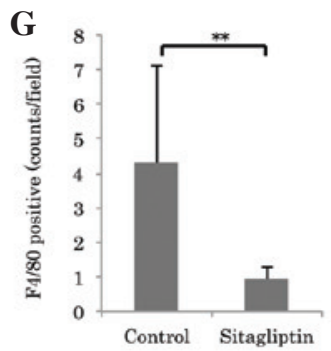

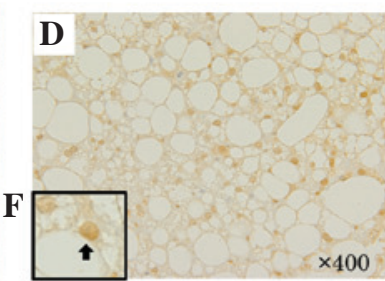

Control

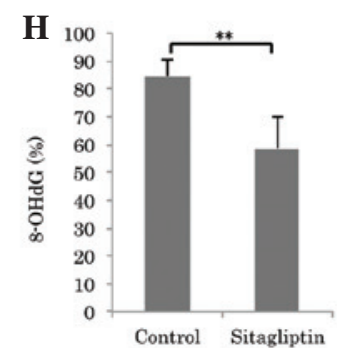

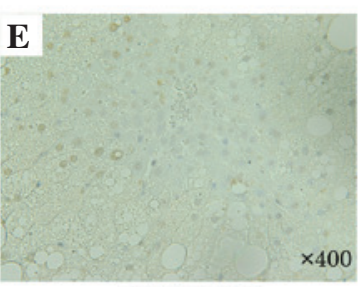

Sitagliptin

4-HNE

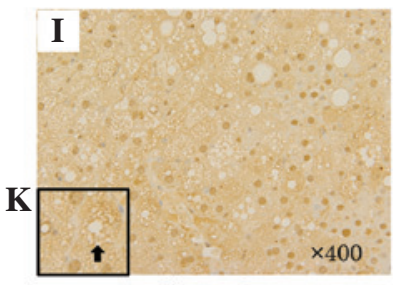

Control

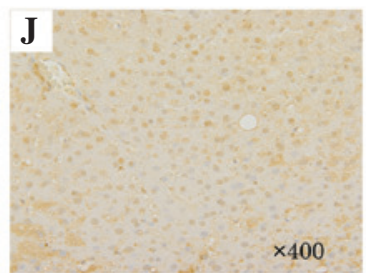

Sitagliptin

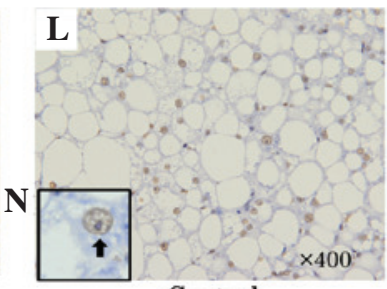

Control
TUNEL

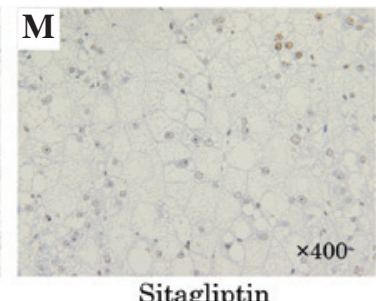

Sitagliptin
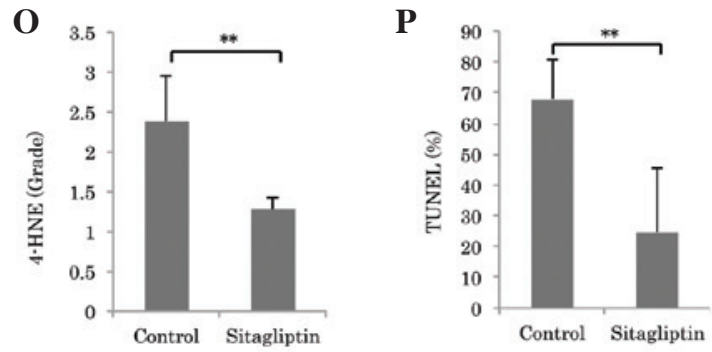

Figure 3. Representative images of F4/80 immunostaining for Kupffer cells (magnification, $\mathrm{x} 400$ ) in the (A) control and (B) sitagliptin groups. (C) Increased magnification $(\mathrm{x} 1,000)$ of immunopositive F4/80 positive cells. Representative immunostaining for 8-OHdG (magnification, $\mathrm{x} 400)$ of the (D) control and (E) sitagliptin groups. (F) A higher magnification of an 8-OHdG positive nucleus (x1,000, arrow). (G) Quantitation of F4/80 immunopositive cells in each group indicated that $\mathrm{F} 4 / 80$ immunopositive cells were significantly decreased in the sitagliptin group compared with the control $\left({ }^{* *} \mathrm{P}<0.01\right)$. Oxidative stress was determined by $8-\mathrm{OHdG}$ and $4-\mathrm{HNE}$ immunostaining. (H) A comparison of $8-\mathrm{OHdG}$ immunopositive cells between the groups $\left.{ }^{(* *} \mathrm{P}<0.01\right)$. Immunostaining for 8-OHdG was significantly decreased in the sitagliptin group compared with the control. Immunostaining for 4-HNE (magnification, x400) in the (I) control and (J) sitagliptin groups. (K) 4-HNE immunopositive cell at a higher magnification (x1,000, arrow). Apoptotic cells were determined by TUNEL immunostaining (magnification, $\mathrm{x} 400)$ in the (L) control and (M) sitagliptin groups. (N) A higher magnification $(\mathrm{x} 1,000)$ of a TUNEL positive nucleus (arrow). (O) A comparison of 4-HNE immunopositive cells between the groups. Immunostaining of 4-HNE was significantly reduced in the sitagliptin group compared with the control $\left({ }^{* *} \mathrm{P}<0.01\right)$. (P) A comparison of the numbers of TUNEL positive cells between groups. The number of TUNEL-positive cells was significantly decreased in the sitagliptin group compared with the control $\left({ }^{* *} \mathrm{P}<0.01\right) .8-\mathrm{OHdG}, 8$-hydroxy-2-deoxyguanosine; 4-HNE, 4-hydroxynonenal; TUNEL, terminal deoxynucleotidyl transferase dUTP nick end labeling.

as follows: $95^{\circ} \mathrm{C}$ for $20 \mathrm{sec}$, followed by 45 cycles of $1 \mathrm{sec}$ at $95^{\circ} \mathrm{C}$ and $20 \mathrm{sec}$ at $60^{\circ} \mathrm{C}$. The relative mRNA expression levels were calculated using the $2^{-\Delta \Delta C T}$ method (20).

Statistical analysis. The significance of the differences between the groups was statistically analyzed using an unpaired Student's t-test. The data were statistically analyzed using StatFlex version 6.0 for Windows software (Artech Co, Ltd., Osaka, Japan). All data are expressed as the mean \pm stan- dard deviation. $\mathrm{P}<0.05$ was considered to indicate a statistically significant difference.

\section{Results}

Characteristics of the mice. As shown in Table I, the body weight of the mice was significantly lower in the sitagliptin group compared with the control group. The liver weight and liver-to-body weight ratio in the sitagliptin group also 
Table II. mRNA expression levels of various genes in the control and sitagliptin groups.

\begin{tabular}{lcc}
\hline mRNA & $\begin{array}{c}\text { Control } \\
\text { group }(\mathrm{n}=10)\end{array}$ & $\begin{array}{c}\text { Sitagliptin } \\
\text { group }(\mathrm{n}=10)\end{array}$ \\
\hline FAS & $6.21 \pm 3.79$ & $1.65 \pm 0.43^{\mathrm{b}}$ \\
SREBP1c & $1.98 \pm 0.62$ & $1.59 \pm 0.42$ \\
PPAR- $\alpha$ & $2.07 \pm 0.63$ & $2.83 \pm 0.59^{\mathrm{b}}$ \\
MTP & $1.63 \pm 0.37$ & $1.44 \pm 0.28$ \\
Procollagen-type I & $24.89 \pm 17.47$ & $8.06 \pm 6.40^{\mathrm{b}}$ \\
TGF- $\beta 1$ & $2.40 \pm 0.46$ & $1.65 \pm 0.47^{\mathrm{b}}$ \\
CTGF & $7.32 \pm 10.93$ & $3.36 \pm 0.91$ \\
TIMP-1 & $11.43 \pm 6.53$ & $4.05 \pm 2.69^{\mathrm{b}}$ \\
TNF- $\alpha$ & $4.81 \pm 2.19$ & $2.64 \pm 0.91^{\mathrm{b}}$ \\
MCP-1 & $8.10 \pm 5.10$ & $4.30 \pm 2.45^{\mathrm{a}}$ \\
\hline
\end{tabular}

The data are presented as the relative mRNA levels compared with $\beta$-actin. ${ }^{\mathrm{a}} \mathrm{P}<0.05$ and ${ }^{\mathrm{b}} \mathrm{P}<0.01$, compared with the control group. FAS, fatty acid synthase; SREBP1c, sterol regulatory element-binding protein 1c; PPAR- $\alpha$, peroxisome proliferator activated receptor- $\alpha$; MTP, microsomal triglyceride transfer protein; TGF- $\beta 1$, transforming growth factor $\beta 1$; CTGF, connective tissue growth factor; TIMP-1, tissue inhibitor of metalloproteinases 1 ; TNF- $\alpha$, tumor necrosis factor- $\alpha$. MCP-1, monocyte chemotactic protein-1.

demonstrated a decreased tendency compared with the control group. Food consumption and visceral fat weight revealed no significant difference between the two groups. The serum levels of AST and ALT also revealed no significant difference between the two groups. The serum glucose was significantly lower in the sitagliptin group compared with the control group at 8 and 12 weeks after the administration of the DPP-IV inhibitor (Fig. 1).

Effects of sitagliptin on hepatic steatosis. To assess the effects of sitagliptin on lipid metabolism, the present study determined the hepatic steatosis area, hepatic lipid contents and gene expression of hepatic lipogenesis, lipolysis and lipid transporter. Oil Red O staining revealed that sitagliptin significantly reduced the area of hepatic steatosis (sitagliptin group, vs. control group; $13.8 \pm 4.3$, vs. $35.4 \pm 16.5 \%$; $\mathrm{P}<0.001$; Fig. $2 \mathrm{~A}-\mathrm{E})$. Hepatic total cholesterol and triglyceride contents in the sitagliptin group were lower compared with the control group (Hepatic cholesterol: Sitagliptin, $31.8 \pm 10.3$,vs.control,37.9 $\pm 9.9 \mathrm{mg} /$ gliver; Triglyceride: Sitagliptin, $741 \pm 276$, vs. control: $894 \pm 359 \mathrm{mg} / \mathrm{g}$ liver), however, not significantly so (Fig. 2F and G). The mRNA expression levels of genes associated with hepatic steatosis were listed in Table II. The mRNA expression of PPAR- $\alpha$ was significantly increased in the sitagliptin group (sitagliptin, vs. control group; $2.83 \pm 0.59$, vs. $2.07 \pm 0.63 ; \mathrm{P}=0.0095)$. The mRNA expression of FAS was significantly decreased in the sitagliptin group (sitagliptin, vs. control group; $1.65 \pm 0.43$, vs. $6.21 \pm 3.78 ; \mathrm{P}=0.0013$ ). The mRNA expression levels of SREBP1c and MTP were reduced in the sitagliptin group compared with the control, however, not significantly so. Taken together, these findings suggested that sitagliptin reduced lipid synthesis and the accumulation in the liver of FLS- $o b / o b$ mice.
Effects of sitagliptin on hepatic fibrosis. To assess the possibility that sitagliptin reduced hepatic fibrosis, the present study determined the antifibrotic effects of sitagliptin in the FLS-ob/ob mice using Sirius red staining, $\alpha$-SMA staining and pro-fibrogenic cytokine gene expression. Sirius red staining revealed that sitagliptin reduced the area of fibrosis compared with the control (sitagliptin, vs. control; $0.74 \pm 0.54$, vs. $2.61 \pm 1.53 \%$; $\mathrm{P}=0.0016$; Fig. $2 \mathrm{H}$, I and M). Since activated HSCs are a major contributor to hepatic fibrogenesis, the present study measured the protein expression of $\alpha$-SMA, which is expressed by HSCs in response to liver injury. Notably, sitagliptin caused a profound decrease in the area of positive $\alpha$-SMA immunostaining compared with the control (sitagliptin, vs. control; $0.23 \pm 0.15$, vs. $0.78 \pm 0.19 \%$; $\mathrm{P}<0.001$; Fig. 2J-L and N), which suggested that this treatment inhibited the activation of HSCs. The mRNA expression of parameters associated with extracellular matrix metabolism in the liver are listed in Table II. Sitagliptin significantly reduced the mRNA expression levels of procollagen I, TGF- $\beta 1$ and TIMP-1 compared with the controls. The mRNA expression of CTGF tended to be lower in the sitagliptin group compared with the control group.

Effects of sitagliptin on inflammatory reactions in the liver. The process of hepatic fibrosis is driven primarily by inflammation in response to liver damage. Sitagliptin markedly reduced the number of $\mathrm{F} 4 / 80$ positive cells, representing liver macrophage Kupffer cells, compared with the control group (sitagliptin, vs. control; $0.95 \pm 0.33$, vs. $4.31 \pm 2.78$; $\mathrm{P}=0.0013$; Fig. 3A-C and G) and reduced the quantity of mRNA for MCP-1 by $53 \%$ and TNF- $\alpha$ by $55 \%$ (Table II).

Effects of sitagliptin on oxidative stress. Oxidative stress is involved in the development of NASH. The present study determined oxidative stress by two methods: $8-\mathrm{OHdG}$ as an index of DNA damage and 4-HNE as an index of a lipid peroxidation. Sitagliptin markedly reduced the ratio of $8-\mathrm{OHdG}$ positive cells in the liver samples compared with the control (sitagliptin, vs. control; 58.6 \pm 11.6 , vs. $84.5 \pm 5.8 \%$; P $<0.001$; Fig. 3D-F and $\mathrm{H})$ and significantly reduced the immunostaining grade for liver 4-HNE (sitagliptin, vs. control; $1.27 \pm 0.16$, vs. $2.38 \pm 0.56$; $\mathrm{P}<0.001$; Fig. 3I-G and N).

Effect of sitagliptin on hepatic apoptosis. Hepatocytes damaged by oxidative stress undergo apoptosis. Sitagliptin significantly reduced the ratio of TUNEL positive cells in the liver samples compared with the control (sitagliptin, vs. control; 68.0 12.9 , vs. 24.8 $\pm 20.6 \%$; P $<0.001$; Fig. 3K-M and O).

\section{Discussion}

The present study revealed that sitagliptin decreased blood glucose level, hepatic lipogenesis, pro-inflammatory cytokines, pro-fibrogenic cytokines and oxidative stress, consequently improving hepatic steatosis, inflammation and fibrosis. The 'two-hit' theory and 'multiple parallel hits' hypothesis have been proposed for the pathophysiology of NAFLD and NASH (21). The first hit is insulin resistance and leads to NAFLD. The following hits, oxidative stress, cytokine production and inflammation increase, result in the development of NASH (22-24). 
Sitagliptin significantly improved hyperglycemia and reduced body weight compared with the controls under the identical dietary intake. The inhibition of DPP-IV by sitagliptin led to the attenuation of incretin degradation, consequently increasing insulin and reducing blood glucose levels. TNF- $\alpha$ leads to insulin resistance by impairing insulin signaling and reducing glucose transporters (22). The reduction of the gene expression of TNF- $\alpha$ in the sitagliptin group also improved insulin resistance. The loss of body weight by DPP-IV inhibitors is suggested to be due to two mechanisms, one of which is the loss of appetite by the inactivation of peptide YY (25). The other is the inhibitory effect on fat absorption from the gut. Notably, another DPP-IV inhibitor, vildagliptin, is reported to reduce the prandial triglyceride response to fat-rich meal intake by $85 \%$ (26). Furthermore, sitagliptin in combination with metformin reduce cholesterol and triglyceride levels (27). In the present study, since food consumption was unaltered between the two mouse groups, the weight loss in the sitagliptin group was likely due to the inhibition of fat absorption from the gut. Trials of weight loss improve liver function and liver histology in NAFLD (28). The improvement of liver histology by sitagliptin may originate from both weight-independent and weight-dependent effects $(29,30)$.

Treatment with sitagliptin activated PPAR- $\alpha$ and attenuated SREBP1c and FAS. Therefore, the present study supported that DPP-IV affected lipid accumulation by the inactivation of PPAR- $\alpha$, which is involved in $\beta$-oxidation of fatty acids, and the activation of SREBP1c and FAS, which are involved in hepatic lipogenesis (31). In the liver of high-fat-fed mice lacking DPP-IV, the expression of PPAR- $\alpha$ is upregulated, whereas the expression of SREBP1c is downregulated (10). SREBP1c stimulates several lipogenic enzymes, including FAS (32). In the present study, sitagliptin inhibited FAS more markedly compared with SREBP1c. This may be explained by the dose-dependency of sitagliptin ( $2 \mathrm{mg} / \mathrm{kg} /$ day). Sitagliptin inhibits plasma DPP-IV activity in a dose-dependent manner, from 0.1 to $3 \mathrm{mg} / \mathrm{kg}$, in mice (33). Administration of a higher dose of sitagliptin may reduce the expression of SREBP1c. MTP transports triglycerides to very low-density lipoprotein. Enhanced expression of this gene (34) promotes the release of excess lipid from NAFLD livers. However, in the present study, sitagliptin revealed no affect on MTP gene expression. From these results, decreased steatosis by sitagliptin was caused by the attenuation of lipogenesis and the stimulation of lipolysis.

The present study demonstrated that sitagliptin reduced hepatic macrophages and Kupffer cells, which were measured by the F4/80 positive cell index. Furthermore, the expression levels of TNF- $\alpha$ and MCP-1 were reduced in the sitagliptin group. Several chemokines are known to be target peptides of DPP-IV (11). MCP-1 [chemokine (C-C motif) ligand 2] is produced by Kupffer cells and HSCs, and promotes hepatic inflammation by recruiting and activating macrophages (35-37). The plasma concentration of MCP-1 is reported to be reduced by treatment with DPP-IV inhibitors in patients with diabetes (38). DPP-IV inhibitors may reduce MCP-1 mediated C-C chemokine receptor type 2 macrophages. From these results, sitagliptin induced a marked reduction in intrahepatic inflammation.
In addition to the significant reduction of $\alpha$-SMA positive cells, activated myofibroblasts/HSCs, reduced hepatic fibrosis area and decreased gene expression of procollagen I, TGF- $\beta 1$ and TIMP- 1 were observed in the sitagliptin group compared with the control group. Similarly, sitagliptin reduced the activation of HSC in MCD fed mice (18). The mechanisms by which sitagliptin attenuated fibrosis are most likely mediated through inhibition of HSC activation. HSCs are activated by TGF- $\beta 1$ or oxidative stress. The present study immunochemically analyzed $8-\mathrm{OHdG}$ and $4-\mathrm{HNE}$ to determine the effects of sitagliptin on oxidative stress. Oxidative stress is pivotal as a factor in liver disease, which progresses from steatosis to steatohepatitis. Fatty acid oxidation represents an important source of reactive oxygen species, which induce lipid peroxidation and initiate DNA damage, which are assessed as 4-HNE and 8-OHdG production, respectively. It was demonstrated that sitagliptin ameliorated 8-OHdG and 4-HNE immunostaining in the liver tissues and attenuated reactive oxygen species production. The present study revealed that sitagliptin suppressed the activation of HSC via the attenuation of oxidative stress and the inhibition of pro-fibrogenic and pro-inflammatory cytokines (TGF- $\beta 1$, TNF- $\alpha$ and MCP-1). Additionally, sitagliptin was reported to directly suppress the proliferation of HSCs in rats (39). Therefore, sitagliptin may directly and indirectly suppress the activation of HSCs.

In conclusion, sitagliptin attenuated the progression of hepatic fibrosis by improving fatty deposition and inhibiting inflammation. This treatment also decreased oxidative stress, and pro-inflammatory and fibrogenic cytokines.

\section{References}

1. Ding X, Saxena NK, Lin S, Gupta N and Anania FA: Exendin-4, a glucagon-like protein-1 (GLP-1) receptor agonist, reverses hepatic steatosis in ob/ob mice. Hepatology 43: 173-181, 2006.

2. Mentzel S, Dijkman HB, Van Son JP, Koene RA and Assmann KJ: Organ distribution of aminopeptidase A and dipeptidyl peptidase IV in normal mice. J Histochem Cytochem 44: 445-461, 1996.

3. Heike M, Möbius U, Knuth A, Meuer S and Meyer zum Büschenfelde KH: Tissue distribution of the T cell activation antigen Ta1. Serological, immunohistochemical and biochemical investigations. Clin Exp Immunol 74: 431-434, 1988.

4. Gorrell MD, Gysbers V and McCaughan GW: CD26: A multifunctional integral membrane and secreted protein of activated lymphocytes. Scand J Immunol 54: 249-264, 2001.

5. Dinjens WN, ten Kate J, Wijnen JT, van der Linden EP, Beek CJ, Lenders MH, Khan PM and Bosman FT: Distribution of adenosine deaminase-complexing protein in murine tissues. J Biol Chem 264: 19215-19220, 1989.

6. Brubaker PL and Drucker DJ: Structure-function of the glucagon receptor family of $\mathrm{G}$ protein-coupled receptors: The glucagon, GIP, GLP-1 and GLP-2 receptors. Receptors Channels 8: 179-188, 2002.

7. Reinehr T, Roth CL, Enriori PJ and Masur K: Changes of dipeptidyl peptidase IV (DPP-IV) in obese children with weight loss: Relationships to peptide YY, pancreatic peptide and insulin sensitivity. J Pediatr Endocrinol Metab 23: 101-108, 2010.

8. Yamabe T, Takakura K, Sugie K, Kitaoka Y, Takeda S, Okubo Y, Teshigawara K, Yodoi J and Hori T: Induction of the $2 \mathrm{~B} 9$ antigen/dipeptidyl peptidase IV/CD26 on human natural killer cells by IL-2, IL-12 or IL-15. Immunology 91: 151-158, 1997.

9. Ohnuma K, Takahashi N, Yamochi T, Hosono O, Dang NH and Morimoto C: Role of CD26/dipeptidyl peptidase IV in human $\mathrm{T}$ cell activation and function. Front Biosci 13: 2299-2310, 2008. 
10. Conarello SL, Li Z, Ronan J, Roy RS, Zhu L, Jiang G, Liu F, Woods J, Zycband E, Moller DE, et al: Mice lacking dipeptidyl peptidase IV are protected against obesity and insulin resistance. Proc Natl Acad Sci USA 100: 6825-6830, 2003

11. Itou M, Kawaguchi T, Taniguchi E and Sata M: Dipeptidyl peptidase-4: A key player in chronic liver disease. World J Gastroenterol 19: 2298-2306, 2013.

12. Miyazaki M, Kato M, Tanaka K, Tanaka M, Kohjima M, Nakamura K, Enjoji M, Nakamuta M, Kotoh K and Takayanagi R Increased hepatic expression of dipeptidyl peptidase- 4 in non-alcoholic fatty liver disease and its association with insulin resistance and glucose metabolism. Mol Med Rep 5: 729-733, 2012.

13. Balaban YH, Korkusuz P, Simsek H, Gokcan H, Gedikoglu G, Pinar A, Hascelik G, Asan E, Hamaloglu E and Tatar G: Dipeptidyl peptidase IV (DDP IV) in NASH patients. Ann Hepatol 6: 242-250, 2007

14. Ben-Shlomo S, Zvibel I, Shnell M, Shlomai A, Chepurko E, Halpern Z, Barzilai N, Oren R and Fishman S: Glucagon-like peptide-1 reduces hepatic lipogenesis via activation of AMP-activated protein kinase. J Hepatol 54: 1214-1223, 2011.

15. Soga M, Kishimoto Y, Kawaguchi J, Nakai Y, Kawamura Y, Inagaki S, Katoh K, Oohara T, Makino S and Oshima I: The FLS mouse: A new inbred strain with spontaneous fatty liver. Lab Anim Sci 49: 269-275, 1999.

16. Soga M, Hashimoto S, Kishimoto Y, Hirasawa T, Makino S and Inagaki S: Insulin resistance, steatohepatitis and hepatocellular carcinoma in a new congenic strain of Fatty Liver Shionogi (FLS) mice with the Lep (ob) gene. Exp Anim 59: 407-419, 2010.

17. Sugihara T, Koda M, Kishina M, Kato J, Tokunaga S, Matono T, Ueki M and Murawaki Y: Fatty liver Shionogi ob/ob mouse: A new candidate for a non-alcoholic steatohepatitis model. Hepatol Res 43: 547-556, 2013

18. Jung YA, Choi YK, Jung GS, Seo HY, Kim HS, Jang BK, Kim JG, Lee IK, Kim MK and Park KG: Sitagliptin attenuates methionine/choline-deficient diet-induced steatohepatitis Diabetes Res Clin Pract 105: 47-57, 2014.

19. McKnight AJ, Macfarlane AJ, Dri P, Turley L, Willis $\mathrm{AC}$ and Gordon S. Molecular cloning of F4/80, a murine macrophage-restricted cell surface glycoprotein with homology to the G-protein-linked transmembrane 7 hormone receptor family. J Biol Chem 271: 486-489, 1996.

20. Livak KJ and Schmittgen TD. Analysis of relative gene expression data usingreal-time quantitative PCR and the 2(-Delta Delta C(T)) Method. Methods 25: 402-408, 2001.

21. Tilg $\mathrm{H}$ and Moschen AR: Evolution of inflammation in nonalcoholic fatty liver disease: The multiple parallel hits hypothesis. Hepatology 52: 1836-1846, 2010.

22. Tessari P, Coracina A, Cosma A and Tiengo A: Hepatic lipid metabolism and non-alcoholic fatty liver disease. Nutr Metab Cardiovasc Dis 19: 291-302, 2009.

23. Angulo P: Nonalcoholic fatty liver disease. N Engl J Med 346: 1221-1231, 2002

24. Youssef W and McCullough AJ: Diabetes mellitus, obesity and hepatic steatosis. Semin Gastrointest Dis 13: 17-30, 2002

25. Ballantyne GH. Peptide YY(1-36) and peptide YY(3-36): Part I. Distribution, release and actions. Obes Surg 16: 651-658, 2006.
26. Matikainen N, Mänttäri S, Schweizer A, Ulvestad A, Mills D, Dunning BE, Foley JE and Taskinen MR: Vildagliptin therapy reduces postprandial intestinal triglyceride-rich lipoprotein particles in patients with type 2 diabetes. Diabetologia 49: 2049-2057, 2006.

27. Scott R, Loeys T, Davies MJ and Engel SS; Sitagliptin Study 801 Group: Efficacy and safety of sitagliptin when added to ongoing metformin therapy in patients with type 2 diabetes. Diabetes Obes Metab 10: 959-969, 2008.

28. Schreuder TC, Verwer BJ, van Nieuwkerk CM and Mulder CJ: Nonalcoholic fatty liver disease: An overview of current insights in pathogenesis, diagnosis and treatment. World J Gastroenterol 14: 2474-2486, 2008.

29. Shirakawa J,Fujii H, Ohnuma K, Sato K, Ito Y, Kaji M, Sakamoto E, Koganei M, Sasaki H, Nagashima Y, et al: Diet-induced adipose tissue inflammation and liver steatosis are prevented by DPP-4 inhibition in diabetic mice. Diabetes 60: 1246-1257, 2011.

30. Foley JE and Jordan J: Weight neutrality with the DPP-4 inhibitor, vildagliptin: Mechanistic basis and clinical experience. Vasc Health Risk Manag 6: 541-548, 2010.

31. Foufelle F and Ferré P: New perspectives in the regulation of hepatic glycolytic and lipogenic genes by insulin and glucose: A role for the transcription factor sterol regulatory element binding protein-1c. Biochem J 366: 377-391, 2002.

32. Bugianesi E, MuCullough AJ and Marchesini G: Insulin resistance: A metabolic pathway to chronic liver disease. Hepatology 42: 987-1000, 2005.

33. Kim D, Wang L, Beconi M, Eiermann GJ, Fisher MH, He H, Hickey GJ, Kowalchick JE, Leiting B, Lyons K, et al: (2R)-4-oxo-4-(3-(trifluoromethyl)-5,6-dihydro $(1,2,4)$ triazolo(4,3-a) pyrazin-7(8H)-yl)-1-(2,4,5-trifluorophenyl) butan-2-amine: A potent, orally active dipeptidyl peptidase IV inhibitor for the treatment of type 2 diabetes. J Med Chem 48: 141-151, 2005.

34. Wetterau JR, Lin MC and Jamil H. Microsomal triglyceride transfer protein. Biochim Biophys Acta 1345: 136-150, 1997.

35. Zamara E, Galastri S, Aleffi S, Petrai I, Aragno M, Mastrocola R, Novo E, Bertolani C, Milani S, Vizzutti F, et al: Prevention of severe toxic liver injury and oxidative stress in MCP-1-deficient mice. J Hepatol 46: 230-238, 2007.

36. Seki E, de Minicis S, Inokuchi S, Taura K, Miyai K, van Rooijen N, Schwabe RF and Brenner DA: CCR 2 promotes hepatic fibrosis in mice. Hepatology 50: 185-197, 2009.

37. Galastri S, Zamara E, Milani S, Novo E, Provenzano A, Delogu W, Vizzutti F, Sutti S, Locatelli I, Navari N, et al: Lack of $\mathrm{CC}$ chemokine ligand 2 differentially affects inflammation and fibrosis according to the genetic background in a murine model of steatohepatitis. Clin Sci (Lond) 123: 459-471, 2012.

38. Fadini GP, Boscaro E, Albiero M, Menegazzo L, Frison V, de Kreutzenberg S, Agostini C, Tiengo A and Avogaro A: The oral dipeptidyl peptidase-4 inhibitor sitagliptin increases circulating endothelial progenitor cells in patients with type 2 diabetes: Possible role of stromal-derived factor-1alpha. Diabetes Care 33: 1607-1609, 2010

39. Kaji K, Yoshiji H, Ikenaka Y, Noguchi R, Aihara Y, Douhara A, Moriya K, Kawaratani H, Shirai Y, Yoshii J, et al: Dipeptidyl peptidase-4 inhibitor attenuates hepatic fibrosis via suppression of activated hepatic stellate cell in rats. J Gastroenterol 49: 481-491, 2013. 